\title{
DEMOCRACIA Y BIOÉTICA
}

\section{Diego Gracia Guillén*}

Resumen: La Bioética, desde hace treinta años ha promovido incesantemente la participación democrática en el ámbito de la relación sanitaria, mediante procedimientos que permiten adoptar decisiones en las cuales se expresa el parecer y los intereses de todos los involucrados. Estos procedimientos dan cuenta de una práctica constante de deliberar en conjunto, con el fin de lograr las soluciones más matizadas y correctas. Esta experiencia de la Bioética permite plantear, de manera amplia, la relación entre Democracia y Bioética, en la medida que es necesario y urgente corregir los déficits democráticos, logrando que ésta no sólo sea participativa sino que también deliberativa.

Palabras Clave: modernidad, democracia, legitimidad, deliberación, participación.

\section{DEMOCRACY AND BIOETHICS}

Abstract: Upon the last 30 years Bioethics has permanently been promoting democratic participation in health care contexts through procedures oriented to decision-making that considers the interests of everyone involved. These procedures imply a continual joined deliberative practice aimed at reaching nuanced and fair solutions. This experience of bioethics allows us to suggest, in a broad sense, the relationship between it and democracy since it has become necessary and urgent to correct democratic deficiencies trying to build it up not only participative but also deliberative.

Keywords: modernity, democracy, legitimacy, deliberation, participation.

\section{DEMOCRACIA E BIOÉTICA}

Resumo: A Bioética há 30 anos vem promovendo incessantemente a participação do diálogo democrático no âmbito da saúde, e o faz mediante procedimentos que permitam tomadas de decisões que expressem os interesses de todos envolvidos. Estes procedimentos exibem a prática constante da deliberação em conjunto, com a finalidade de alcançar soluções mais harmônicas e corretas. Esta experiência da Bioética permite sugerir, de maneira ampla, a relação entre Democracia e Bioética, na medida em que se faz necessário e urgente corrigir as deficiências da democracia, buscando construí-la não somente participativa, mas, sobretudo deliberativa.

Palavras chaves: modernidade, democracia, legitimidade, deliberação, participação.

* Doctor en Medicina. Director, Departamento de Salud Pública e Historia de la Ciencia, Universidad Complutense de Madrid, España. Correspondencia: dgracia@fcs.es 


\section{Introducción}

El mundo moderno ha asistido a la pérdida de la homogeneidad cultural y creencial. De un sistema basado en la uniformidad de valores, hemos pasado a otro en que la pluralidad y el respeto de la pluralidad han cobrado el primer plano. En la vida religiosa, en la moral, en la política, hemos pasado de sistemas basados en el "código único" a otros que colocan en primer término el respeto del "código múltiple". Utilizando una célebre expresión de Max Weber, cabe decir que hemos pasado del "monoteísmo axiológico" al "politeísmo axiológico".

Esto es visto por muchos, no sin nostalgia, como una pérdida, como una gran pérdida. Se añora la situación pasada, en que la homogeneidad era grande y parecía posible saber claramente dónde estaba la verdad y dónde el error. En el fondo, se trataba de trasladar a la sociedad humana categorías escatológicas. Recuérdese el texto del libro XIV (28) de La ciudad de Dios, de San Agustín: Fecerunt itaque civitates duas amores duo: terrenam scilicet amor sui usque ad contemptum Dei, caelestem vero, amor Dei usque ad contemptum sui. También aquí, en la tierra, habría dos ciudades, y debería haber dos, la ciudad de los que están en la verdad y la de quienes se hallan en el error. Así planteadas las cosas, es evidente que ni en religión, ni en ética, ni en política, hay espacio para el pluralismo. Está el espacio de la verdad y el espacio del error. Y la vida en la tierra debe entenderse como la batalla sin cuartel contra las fuerzas del error y del mal.

El problema es que esto puede no ser tan claro. “¿Qué es la verdad?”, venimos preguntándonos al menos desde los tiempos en que Pilatos lanzó esta pregunta, que por cierto quedó sin respuesta. ¿Y qué es el bien?

Toda la historia de la filosofía y de la cultura es el intento de responder a estas dos cuestiones, y a algunas más. Y el resultado no ha sido, ni mucho menos, tan positivo como cabría esperar. La verdad no es categoría humana, sino divina. La verdad se nos escapa continuamente. Los seres humanos no podemos definirnos como "los verdaderos", "los veraces", como, según Nietzsche, se definían a sí mismos los primeros nobles, sino, más humildemente, como "los buscadores de la verdad". La verdad no es tanto algo que se alcanza y se posee, cuanto un camino, un talante, un modo de ser o de vivir en perpetua e incesante búsqueda. Recuérdese aquello de que "quien busca encuentra". Quizá esto se debe a que lo más importante es precisamente la búsqueda, el estado de búsqueda permanente, el amor a la verdad, a pesar de que ésta se nos escape de entre las manos. Quizá lo más importante no es la verdad sino el amor a la verdad. Esto es lo que llevó a los griegos a no considerarse sophói, sabios, término que en el rigor de los términos no podía aplicarse más que a Dios, sino philó-sophoi, amigos de la sabiduría, amantes de la sabiduría, convencidos como estaban de que la sabiduría total no la alcanzarían nunca, pero que su obligación consistía en vivir orientados hacia ella, en tensión de búsqueda hacia ella.

Ahora bien, si esto es así, entonces cabe concluir que no hay dos ciudades, la de la verdad y la del error y que, en principio, todos los que buscan la verdad merecen consideración y respeto, aunque no lleguen a ella, o aunque lleguen a una verdad que no coincide parcialmente con la nuestra. ¿Quién puede considerarse en posesión de la verdad?

A partir de aquí es como hay que plantear el problema del pluralismo y de la democracia. En lo que sigue, voy a intentar exponer sus dimensiones fundamentales, abordando tres cuestiones. La primera es el problema epistemológico que se esconde tras la cuestión ¿qué es la verdad? Se trata de conocer las respuestas que se han dado a esta pregunta y el modo cómo hoy podemos intentar contestarla. La segunda parte analizará la evolución del pluralismo dentro de nuestra sociedad occidental; por tanto, la aparición de la democracia y de las diferentes formas de su legitimación. La tercera versará sobre el 
problema actual de legitimación moral del pluralismo y, más en concreto, sobre las democracias participativa y deliberativa. Y en la cuarta y última distinguiremos entre democracia social y democracia política, defendiendo la tesis de que la primera es indudable que no puede entenderse más que como un proceso de participación y deliberación. Es posible que la democracia política no pueda ser más que representativa, pero aun así resulta necesario concluir que esa representación sólo será adecuada si en la base hay una sociedad que ejerce la democracia participativa y deliberativa. Pues bien, la función básica de la bioética está en el trabajo social, en orden a promover la participación y la deliberación en los procesos de toma de decisiones sobre la vida.

\section{El problema epistemológico: la crisis de la razón}

La filosofía clásica creyó en la capacidad del lógos o la razón para comprender la realidad en su estructura interna. De ahí que definieran la verdad en términos de homoíosis o adaequatio. Recuérdese la definición clásica de verdad, adaequatio intellectus et rei. Esa adecuación no sólo es posible sino necesaria. La realidad, la naturaleza, $p h+$ sis, tiene un orden interno, una razón interna, un lógos, lo que los estoicos llamaron el lógos spermatikós, cuyo conocimiento es tarea del filósofo, y su aplicación, del político. Esto explica por qué Platón consideraba que el gobernante debía ser a la vez rey y filósofo. No se entiende la historia del mundo antiguo y medieval al margen de estas cuestiones.

Pero el mundo moderno empezó a tener razones muy serias para desconfiar de que la naturaleza tuviera un lógos tan claro como el que los griegos postularon, que nosotros fuéramos capaces de conocerlo y que la verdad debiera definirse en términos de homoíosis. Comienza así un segundo período en la historia del pensamiento, en que la verdad no se va a buscar fuera de nosotros, en la naturaleza, sino dentro del ser humano, en su razón. Las verdades por antonomasia son las verdades de razón. Éste va a ser el gran intento de la filosofía moderna, de Descartes a Hegel, reconstruir la idea de verdad desde la razón y no desde la naturaleza.

Lo que sucede es que esto terminó también en fracaso. Es el fenómeno conocido en historia de la filosofía con el nombre de "crisis de la razón" (1, pp.39-51). Esa crisis se fue evidenciando poco a poco, desde la muerte de Hegel, en 1831, hasta las primeras décadas del siglo XX. El empirismo de los siglos XVII y XVIII demostró que los juicios sintéticos de carácter universal carecen de verdad, aunque sólo sea porque su base empírica no es nunca universal, lo cual les priva de certeza y les dota sólo de probabilidad. La única vía para elaborar una metafísica con pretensiones de verdad, es acudir a los otros juicios, los analíticos, que en última instancia son los propios de Dios. Tal fue el intento del racionalismo, que a la postre no fue otra cosa que teología racional. E1 evidente fracaso de esta vía llevó a los idealistas alemanes a probar otra salida, distinguiendo en el orden de los juicios sintéticos dos niveles, el específico del entendimiento y el propio de la razón. Cuando esta vía también se cerró, con la muerte de Hegel, empezó a cundir la sospecha de que Hume tenía razón, que los juicios de experiencia, sobre todo cuando tienen forma universal, no pueden ser nunca verdaderos, no pueden ser del todo verdaderos sino a lo más verosímiles. Esto lo fue corroborando poco a poco el saber más fiable basado en datos empíricos que se tenía en el siglo XIX y tenemos hoy, la ciencia. Newton todavía pudo pensar que sus leyes eran absolutamente verdaderas. Laplace, a comienzos del siglo XIX, aún pudo decir que Dios había creado un universo y Newton había descubierto sus leyes. Casi nadie, cincuenta o cien años después, se hubiera atrevido a repetir esas palabras. La razón sintética se había ido haciendo consciente de sus límites, que muchos 
vivenciaron como fracaso.

Pero la razón analítica no ha seguido mejor suerte. En contra de lo que los racionalistas pensaron, la razón analítica dista mucho de ser por completo coherente y en consecuencia absolutamente verdadera. La demostración la dio el gran programa que se inició en la segunda mitad del siglo XIX y duró hasta las primeras décadas del XX, el intento de formalización de la matemática $\mathrm{y}$, a partir de ahí, de unificación bajo un sistema de leyes absolutamente precisas de las dos disciplinas paradigmáticas del uso analítico de la razón, la lógica y la matemática. Es bien sabido que ese ambicioso programa de formalización acabó en fracaso al comprobarse que todo proceso formal, por ambicioso que sea, conduce necesariamente a paradojas. Diversos autores fueron formulando una tras otra la multitud de paradojas a que dio lugar el intento de formalización de la razón analítica. Y Kurt Gödel, en 1930, demostró con su teorema de la incompletitud de los sistemas algebraicos que esas paradojas no se deben a defectos de construcción, y que todo sistema algebraico y, a la postre, todo sistema formal es por necesidad incompleto.

Estos debates propios de la lógica formal repercutieron inmediatamente en todo el resto de disciplinas filosóficas, incluida la ética. La filosofía del siglo XX se ha visto en la necesidad de pensar todas las ramas del saber filosófico, la metafísica y la ética incluidas, una vez asumido el fracaso de la razón. Las vías para conseguirlo han sido varias. En el mundo anglosajón se impuso el llamado método analítico. En Europa, otro alternativo, el método fenomenológico. Por más que las diferencias entre ellos fueran enormes, ambos coincidían en su escepticismo ante la razón filosófica, tal como ésta se había venido manifestando y expresando hasta entonces. En ambos movimientos la influencia de Hume fue enorme. Y si han querido hacer metafísica, tanto los de un lado como los de otro, han tenido que hacerla de un modo completamente distinto al de épocas anteriores. Las verdades metafísicas, si existen, tienen que darse en niveles previos y distintos a los de la razón clásica. Sin esto no se entiende la metafísica del siglo XX.

Lo mismo cabe decir de la ética. La ética del siglo XX es distinta, tiene que ser distinta a la de cualquier época anterior. Ya no es posible construir una ethica more geometrico demonstrata, como pretendió el racionalista Espinoza. Los juicios normativos son por definición sintéticos. Y si es así, carece de sentido la pretensión, tan frecuente hasta ayer mismo, de considerarlos absolutos y sin excepciones. Hoy no existe más que una vía para afirmar principios deontológicos como absolutos y es la apelación a instancias no racionales, o no completamente racionales, como las creencias y las emociones. Es, exactamente, lo que Weber entendía por Gesinnungsethik. Frente a esas éticas de la convicción, el siglo XX ha intentado elaborar unas éticas basadas en la idea de responsabilidad; es lo que Max Weber denominó Verantwortungsethik (2).

No se entiende gran parte de la ética del siglo XX desligada de este contexto. Precisamente porque los principios deontológicos no son absolutos, es necesario aplicarlos a cada caso tras un detenido análisis del contexto, ya que de otro modo la decisión no podría considerarse responsable. Quizá ahora se entienda de dónde sale la distinción de Beauchamp y Childress, tan conocida en el mundo de la bioética, entre deberes prima facie y deberes reales y efectivos. Si las normas prima facie fueran absolutas, se podría tomar la decisión final a partir de ellas, sin más pasos intermedios. Quizá es la medicina uno de los campos que demuestra palmariamente el carácter irreal de ese modo de pensar. Esta es la vía propia de las éticas de la responsabilidad, dentro de las cuales hay que situar, en un lugar preeminente, la bioética. 


\section{El problema político: la legitimación de la democracia}

El tema de la legitimación de la democracia está hoy más vivo que nunca. Esto se debe, probablemente, a que el modo de enfocarlo ha sufrido en los últimos años importantes modificaciones. Si en la discusión clásica se intentaba demostrar la superioridad moral y política de la democracia sobre los otros regímenes políticos clásicos (monarquía, oligarquía, tiranía, etc.), hoy la perspectiva es completamente distinta. Una vez aceptado que la democracia es un valor mínimo, irrenunciable por cualquier sociedad política, la cuestión que se plantea es la de cómo debe entenderse esta vida democrática a fin de que pueda considerarse éticamente digna. Diríase que si en el pasado la justificación de la democracia se intentaba hacer por vía retrógrada, comparándola con los otros sistemas políticos al uso en la historia de Occidente, ahora los problemas de legitimación se presentan por vía anterógrada, habida cuenta de los efectos que nuestras decisiones tienen para el futuro de la Humanidad sobre el planeta. Por tanto, cuando se habla de "legitimación de la democracia", no es para ponerla contra las cuerdas, defendiendo cualquier otro tipo de actividad política, sino para hacer de ella un sistema de veras coherente y riguroso desde el punto de vista ético y humano. A esto es a lo que se refieren, por ejemplo, los últimos representantes de la Escuela de Francfort, y en particular Jürgen Habermas, en sus múltiples estudios sobre el tema.

No hay duda de que hoy estamos atravesando una crisis de legitimación del sistema democrático. Tampoco la hay de que esta crisis trae a la memoria otras ya habidas tiempo atrás. Sabemos que cada generación de derechos humanos se ha correspondido históricamente con un proceso de legitimación del sistema democrático. Los derechos humanos de primera generación sirvieron para legitimar la democracia formal frente al Estado absolutista. Fue algo, posiblemente mucho, pero no todo. De hecho, esa democracia liberal no trajo la justicia a los pueblos, sino que más bien legitimó el dominio de una clase social, la burguesía, sobre las demás. Así se explica que desde mediados del siglo XIX se viera la necesidad de legitimar de nuevo la democracia, introduciendo una nueva tabla de derechos humanos, los derechos humanos de segunda generación, también llamados derechos de crédito. Su función fue la de compensar el sistema de libertades formales, propio de la democracia liberal, con un amplio conjunto de medidas tendentes a conseguir una mayor igualdad de bienes. Así, la democracia formal se transformó en democracia material. Al Estado liberal le sucedió el Estado social (3). Hoy nos hallamos probablemente en una situación pareja a la de mediados del siglo pasado. El problema está en que ahora ya no consideramos suficiente la mera aposición de los derechos económicos, sociales y culturales a los derechos civiles y políticos, para legitimar el sistema democrático. A pesar de estos derechos, la injusticia sigue siendo una constante del sistema democrático. Parece, pues, que la democracia no puede identificarse sin más con el Estado social, como éste demostró que tampoco podía seguirse identificando con el Estado liberal. Probablemente hay que ir más allá de ambos. ¿Hacia dónde? Hacia un "Estado participativo y deliberativo", basado en la democracia participativa, y no sólo en la liberal o en la social.

Este es un tema tan espinoso como irrenunciable. El déficit democrático lo es siempre de participación. Todos estamos conscientes de que la participación del ciudadano en el sistema político, tanto legislativo como ejecutivo, es torpe e imperfecta. Pero esto no es nuevo; ha acompañado a la democracia desde sus mismos orígenes. La novedad está en que en el rápido proceso de planetarización de la vida, propio del siglo $\mathrm{XX}$, las decisiones políticas de cualquier Estado (económicas, militares, etc.) repercuten en todo el resto de la Tierra. Nunca 
la vida política y social ha estado tan interconectada como ahora. Los acuerdos de cualquier Parlamento afectan a todo el resto de la Humanidad, no sólo de la presente, sino quizá también de la futura. Ahora bien, el principio básico de la vida democrática es que deben poder participar en la toma de decisiones o, al menos deben ser tenidos en cuenta, todos los afectados por un acto o una decisión, tanto actuales como virtuales. Si no se hace así, si las leyes se dictan en beneficio de unos pocos y en perjuicio de los demás, entonces hay que concluir que aún no hemos salido de la época del despotismo y la tiranía. Tendremos democracia "formal", o incluso democracia "social", pero desde luego no democracia "participativa", que es la única éticamente defendible en una época como la nuestra, en que el poder político es tal que tiene en sus manos el presente y el futuro de la vida sobre el planeta.

Esto que llamo Estado participativo se basa en la tesis de que las democracias actuales son muy poco democráticas, y sólo podrán serlo completamente si son capaces de tomar decisiones teniendo en cuenta los intereses, no ya de los parlamentarios que hacen las leyes o de los políticos que las aplican, ni tampoco de toda la sociedad a la que representan, sino de toda la Humanidad, es decir, de todos los hombres presentes y futuros. Hoy, en los albores del tercer milenio, no podemos conformarnos con menos. La crisis de legitimidad de nuestra democracia se debe a que es poco democrática; es "formal" y "materialmente" democrática, pero no "realmente" democrática.

Son de sobra conocidos los fallos terribles del parlamentarismo en las democracias meramente formales y materiales. Estos fallos se objetivan en el recurso a la objeción de conciencia, a los tribunales de justicia (un poder no legitimado democráticamente), la extraparlamentarización de la toma de decisiones (algo perfectamente constatable en los usos de la Comunidad Europea), etc. Todos son síntomas de lo que puede denominarse un "déficit democrático". Se dirá que este déficit no es inherente al concepto "ideal" de la democracia, pero sí a su ejercicio "real". Ahora bien, si esto es así, entonces tiene razón Jürgen Habermas cuando afirma que las decisiones democráticas no serán nunca verdaderamente representativas más que cuando tengan en cuenta, al menos idealmente, a todos los seres humanos, es decir, cuando se hagan a la vista de lo que él llama la "comunidad ideal de comunicación" (4). A esto es a lo que conduce el descubrimiento de los hoy llamados derechos humanos de tercera generación: a replantear la legitimidad de los sistemas democráticos y a afirmar que ninguna democracia fáctica es legítima a menos que sea capaz de tener en cuenta los intereses de todos los seres humanos, tanto presentes como futuros (5).

\section{El problema moral: las propuestas de la democracia participativa y deliberativa}

Alguien dirá que todo eso ya no es una cuestión jurídica ni política, sino ética. Y en efecto, así es. Hace ahora dos siglos que Kant formuló su imperativo categórico: "Obra de tal modo que la máxima de tu voluntad pueda valer siempre, al mismo tiempo, como principio de una legislación universal" (6, p.149). O, según la fórmula de la Introducción a la metafísica de las costumbres: "Obra de tal modo que uses la humanidad tanto en tu persona como en la persona de cualquier otro siempre como fin, nunca meramente como medio" ( 7, p.189). Cabe preguntarse qué entendía Kant por Humanidad cuando escribía estas frases. Probablemente pensaba que la Humanidad se circunscribía al ámbito de sus contemporáneos. ¿Cómo tener en cuenta en los juicios éticos a los ya muertos, o a los aún no nacidos? Al moralista Kant le sucedía como a tantos juristas actuales, que le costaba concebir a los seres humanos futuros como sujetos de derechos.

Hoy la perspectiva es muy distinta. Para verlo basta abrir un libro que hoy goza de justa fama, The Imperative of Responsibility, del 
filósofo Hans Jonas. Este filósofo cree que por vez primera en la historia hemos de introducir en el imperativo categórico no sólo la Humanidad presente sino también la futura. En consecuencia, dice, el imperativo categórico debe reformularse en los siguientes términos: "Obra de tal modo que los efectos de tu actuación sean compatibles con la permanencia de una vida humana auténtica en la Tierra"; o también: "Obra de tal modo que los efectos de tu acción no sean destructivos para la futura posibilidad de esa vida"; o, simplemente, "No pongas en peligro las condiciones de la continuidad indefinida de la humanidad en la Tierra" (8, p.40).

Otro autor, Apel, ha afirmado que la ética sólo existe cuando se considera a los seres humanos como "una comunidad de seres racionales con igualdad de derechos en tanto que seres que son fines en sí mismos". Todos actuamos por intereses, y es legítimo que así sea. Pero los intereses no son morales si no son generalizables, es decir, si no pueden ser aceptados como tales por la comunidad ideal de argumentación, en la que potencialmente han de estar incluidos todos los hombres, tanto presentes como futuros. Esto es lo que Apel entiende por "consenso", la posibilidad de acuerdo sobre intereses por parte de la comunidad ideal de argumentación. Cuando quienes se ponen de acuerdo son un grupo fáctico, pero no el grupo que idealmente reúne a todos los hombres, entonces el acuerdo no es racional, ni por tanto moral, sino meramente "táctico" o "estratégico". Este sería el acuerdo a que pueden llegar todos los hombres de un grupo, o hasta de un país, por puros intereses particulares. Es la volonté de tous de Rousseau, en tanto que el consenso racional es el propio de la volonté générale. El problema de la moral civil, como el de la democracia, es siempre el mismo: la búsqueda de la volonté générale, y no meramente de la volonté de tous. Entre una y otra hay la misma diferencia que entre el "bien común" y los "intereses particulares". En su opúsculo sobre La paz perpetua Kant distinguió entre el "moralista político", es decir, el hombre que utiliza la moral para sus intereses políticos, $y$ aquel otro que busca el tratar a todos los seres humanos como fines, no como medios, y a la Humanidad - presente y futura-como reino de los fines. Cuando se actúa conforme a este segundo criterio, la vida civil es verdaderamente ética, y el gobernante adquiere la categoría de lo que Kant llamaba "político moral"

(9, pp.133-150). Sólo entonces existe la verdadera democracia, y quedan asegurados los derechos de todos los hombres, tanto presentes como futuros.

\section{La bioética entre la democracia social y la democracia política}

El sistema sanitario es un sector del sistema social entero, y reproduce prácticamente todos los problemas del sistema en su conjunto. Las relaciones humanas en medicina pueden establecerse, y de hecho se han establecido, de acuerdo con los mismos esquemas que en la vida sociopolítica en general. Como en ella, las relaciones sanitarias han sido tradicionalmente "paternalistas." El término alude al tipo de vínculo que establecen los padres con sus hijos menores de edad. Se supone que los padres quieren siempre lo mejor para los hijos, pero sin contar con su voluntad. De ahí que en la relación clínica clásica el enfermo estuviera sometido a un fuerte proceso de infantilización. Se suponía que la enfermedad hacía al paciente vulnerable no sólo desde el punto de vista físico sino también desde el moral. Por el propio hecho de la enfermedad, pues, todo enfermo debía ser considerado un incompetente moral. No podía ni debía tomar decisiones y la única virtud moral exigible al paciente era la "obediencia”. El buen médico era el que mandaba con autoridad y el buen paciente, el que sabía obedecer. El mandato del médico se ha basado clásicamente en dos principios morales, hoy conocidos con los nombres de No-maleficencia y Beneficencia. La tradición médica nunca los distinguió claramente, como se advierte ya en la famosa sentencia hipocrática que pide al médico 
"favorecer [beneficencia] o al menos no perjudicar [no-maleficencia]"i. En esa identificación de no-maleficencia y beneficencia estuvo la raíz de su paternalismo. Naturalmente, la relación es paternalista cuando el médico se guía por estos principios, y busca el máximo bien para su paciente aun en contra de su voluntad. Puede suceder, y de hecho ha sucedido innumerables veces en la historia, que el médico anteponga sus intereses personales a los del paciente. En ese caso, su verdadero móvil ya no son los principios éticos de Nomaleficencia y de Beneficencia, razón por la cual la relación tampoco merece ya el título de "paternalista". ¿Cómo denominarla entonces? Aristóteles dice que el padre manda al hijo buscando el beneficio del hijo y no el propio beneficio; eso es lo que él entiende por paternalismo. Pero él distingue la relación paternalista, propia de la relación del padre con sus hijos, de la relación despótica, es decir, la que establece el señor con sus esclavos. El señor, dice Aristóteles, manda al esclavo buscando el propio beneficio y no el beneficio del esclavo, aunque secundariamente deba buscar también el beneficio del esclavo, pues si éste muere acaba el dominio del señor sobre el esclavo. La relación despótica es, para él, éticamente correcta. No lo sería, sin embargo, ampliar el tipo de relación despótica a la vida política. Eso es lo que constituye la "tiranía". En ella se organizan las relaciones políticas de acuerdo con el modelo despótico, no con el paternalista. Aristóteles condena muy duramente la tiranía, ya que consiste en el manejo despótico de las relaciones políticas, lo cual es inadecuado, dado que se trata a los ciudadanos, que son los únicos con capacidad política, como si fueran esclavos. Así, pues, como el despotismo merece un juicio moral negativo, la tiranía, no. Para Aristóteles la tiranía es la perversión del paternalismo. Y como el paternalismo es el régimen mejor imaginable,

i Epidemias I,11, en Tratados hipocráticos, Vol. 5, Madrid: Gredos; 1989. p. 63. la tiranía es también el régimen peor imaginable. Corruptio iptimi pessima, escribió. No hay duda que la estructura vertical o de dominación de la relación clínica ha estado oscilando secularmente entre estos dos extremos, el positivo del paternalismo y el negativo de la tiranía.

De todos modos, en nuestro siglo este modelo ha entrado en franca regresión. Y ello aunque sólo sea porque el ejercicio de la medicina en equipo ha hecho que la dominación del paciente se halle compartida por un grupo de profesionales más o menos numeroso. La relación ya no es, por eso, "monárquica", dado que el poder no está en una sola mano, sino, por seguir utilizando la metáfora política, "oligárquica", toda vez que el poder sobre el paciente se concentra en pocas manos, las de los profesionales de la salud.

Naturalmente, las características básicas de la relación paternalista no desaparecen por el hecho de que el médico comparta su poder con otros médicos y profesionales de la salud. Su estructura sigue siendo vertical y paternalista (o tirana). Lo que sí sucede es que se relajan o desaparecen algunas notas muy peculiares de la fase anterior. La más evidente es, sin duda, la pérdida de valor de la confidencialidad y el secreto. A todo lo largo del periodo de vigencia del primer modelo, ese principio se respetó escrupulosamente, en tanto que en este segundo, quizá por el propio proceso de dilución de las responsabilidades, la conciencia del secreto ha ido debilitándose progresivamente, hasta casi desaparecer. De ahí que, como se ha denunciado tantas veces, la relación clínica haya tenido algunos caracteres más negativos en nuestro siglo que en la época de la clásica relación paternalista.

De todos modos, tampoco la estructura que hemos denominado oligárquica sirve para interpretar y explicar correctamente la situación actual. El proceso de emancipación de los pacientes que se inició en la segunda mitad de la década de los años sesenta, y que desde entonces ha progresado ininterrumpidamente, 
ha hecho la relación progresivamente más horizontal. Si los códigos de derechos de los enfermos han significado algo, ha sido la ruptura del viejo principio de que la enfermedad supone necesariamente la incapacidad moral y que, por tanto, la única salvación no sólo física sino también moral del enfermo estaba en la obediencia de los mandatos del médico. Lo que esos códigos han reivindicado es el derecho y hasta la obligación de todo usuario de los servicios de salud, que posea suficiente capacidad o competencia, de tomar las decisiones sobre su propio cuerpo, en función de su propio proyecto de vida. Ahora ya no hay sólo una ética, la del médico, regida por el principio de No-maleficencia, sino también otra, la del enfermo, basada en el principio ético de Autonomía. No existe uno, sino dos códigos morales, que muchas veces no entrarán en conflicto, pero otras sí, precisamente porque la toma de decisiones es un proceso ahora compartido, común. No se trata de ver la decisión final como un equilibrio entre las opiniones del médico y del paciente, sino como el punto final de un largo proceso de adaptación y convergencia entre la información que el médico posee y los deseos y los valores de que es depositario el paciente. En ese proceso, por tanto, las dos partes son activas. No hay un polo "agente" y el otro "paciente". Por eso cabe decir que ahora la estructura se ha horizontalizado y que, como todos son ya beligerantes en el proceso de toma de decisiones, ésta ha dejado de ser monárquica y oligárquica para convertirse en claramente "democrática" (10, p.69).

Conviene analizar con mayor detalle este tipo de relación que hemos llamado democrática. El término democracia procede de la teoría política. Pero cuando lo aplicamos a la relación sanitaria, es obvio que lo estamos trasponiendo a otro ámbito, el de la vida social. La matización no carece de importancia, porque no es evidente que lo que es válido

ii A este respecto el excelente libro de Amy Gutmann, La educación democrática: una teoría politica de la educación. Barcelona, Paidos, 2001. en uno de esos ámbitos pueda aplicarse al otro. Pudo serlo, quizá, en otras épocas, cuando la vida política venía a identificarse con la vida social, es decir, cuando no se diferenciaban sociedad y Estado. Esto sucedió en todas las culturas primitivas, y en la misma cultura clásica existe la tendencia a considerar que el Estado es la perfección de la vida social, es decir, la estructura social perfecta. Esto es lo que dicen Platón y Aristóteles, y eso es lo que lleva a este último a afirmar, en las primeras líneas de su Política, que la pólis, que podemos traducir por sociedad o Estado, es una koinonía, esto es, una estructura natural (11).

Cuando se piensa así, no hay duda que el orden social y el político se confunden y que el lenguaje de uno de esos niveles es transponible al otro. Pero si algo hizo el mundo moderno fue acabar con ese modo de plantear el problema. Para la mentalidad liberal moderna, sociedad y Estado se diferencian radicalmente. La sociedad es una estructura natural, en tanto que el Estado es el resultado de un acto de voluntad, el contrato social. Antes de él hay sociedad, pero no Estado. En el llamado estado de naturaleza hay sociedad pero no hay Estado.

Pues bien, el concepto de democracia puede utilizarse en cada uno de esos dos niveles, en el de la sociedad y en el del Estado. No está dicho en ninguna parte que el término signifique lo mismo en uno y en otro. En el orden social, la democracia significa, cuando menos, dos cosas: generalización del conocimiento y participación en el proceso de toma de decisiones. Las relaciones sociales se democratizan cuando se permite a los individuos participar en la toma de las decisiones, una vez adecuadamente formados e informados. Por tanto, democracia social es participación, tanto en el conocimiento como en la toma de decisiones. De ahí que la democracia social sea y no pueda no ser "democracia participativa" ( 12)i i . Eso es, por ejemplo, lo que ha promovido la bioética en Medicina. El consentimiento informado no es otra cosa que esto, el proceso de información y participación de los pacientes en el proceso 
de toma de decisiones. La relación sanitaria no es en principio una relación política sino social, y la bioética ha promovido la participación democrática, mediante el procedimiento de la toma de decisiones. Este es el gran éxito que la bioética tiene en su haber, tras treinta años de trabajo.

Pero la democracia social no puede terminar ahí, no termina ahí de hecho. Porque no se trata sólo de generalizar el conocimiento y permitir la participación en la toma de decisiones. Se trata también y sobre todo de asumir como un principio que la verdad no la posee nadie a priori, que hemos de irla conquistando todos en conjunto y colaborativamente y que, por tanto, tenemos que dar razones de las posturas que mantenemos, escuchar y entender las razones de los demás, y de ese modo ir ajustando y modificando las nuestras. De lo que se trata, pues, es de deliberar en conjunto, a fin de llegar a soluciones más matizadas y correctas. Sin deliberación conjunta no habrá nunca auténtica democracia. De ahí que cada vez se insista más en la necesidad de que la democracia social no sea sólo participativa sino también deliberativa. Es la llamada "democracia deliberativa", algo que nuestras sociedades están muy lejos de alcanzar. A mí no me cabe duda de que la bioética está llamada a jugar un importantísimo papel en este sentido. Pero también tengo claro que aún no lo ha conseguido. Ésta es, quizá, su gran tarea pendiente. La bioética es un proceso de deliberación individual y colectiva, en orden a buscar el perfeccionamiento de la vida humana, tanto individual como sobre todo colectiva. La función de los "Comités de Ética" es precisamente ésta.

Hasta aquí nos hemos referido a la democracia social. ¿Son transponibles los esquemas anteriores al ámbito de la democracia política? Puede ser que sí, pero ello no es, en cualquier caso, evidente de suyo. No están completamente convencidos de que la vida política deba regirse por los criterios de la democracia participativa más que aquéllos que identifican desde el comienzo sociedad y
Estado, mejor aún, aquéllos que en la sociedad moderna (en las sociedades antiguas ya vimos que sociedad y Estado son difícilmente distinguibles) niegan la identidad de uno de esos términos, por lo general el segundo. El anarquismo, concretamente, ha considerado siempre que la sociedad debe autogobernarse mediante procedimientos participativos y asamblearios. Así viene pensando desde sus mismos orígenes, en el siglo XVIII. Ya entonces se le opuso otra teoría, que había de triunfar en las diferentes revoluciones liberales. Según ésta, la democracia política no puede ser participativa sino representativa (13). Quizá sea así. En cualquier caso, es evidente que sólo una sociedad en que se instauren como procedimientos la democracia participativa $\mathrm{y}$ deliberativa, podría dar de sí un auténtico sistema político de democracia participativa (14). Lo contrario sería simplemente ilusorio.

La bioética es un procedimiento de participación y deliberación social. Lo que intenta es desarrollar la participación y la deliberación en el nivel de la actividad privada, de la vida social, la que se rige por los principios éticos de Autonomía y Beneficencia. Se trata, pues, de promover la participación y deliberación en el horizonte de las éticas de máximos, en un intento por mejorar la calidad y la corrección de las decisiones que se toman en ese ámbito: mayor respeto a los valores de las personas, deliberación más cuidadosa sobre todos los factores en juego, etc. Por supuesto, esa deliberación tiene un marco de referencia $y$, por tanto, un límite, que es el que define la ética de mínimos, por tanto los principios éticos de No-maleficencia y de Justicia. El contenido público o común de éstos quizá deba establecerse por vías representativas. Pero en cualquier caso, es evidente que sólo una sociedad con redes de participación y deliberación estará en condiciones adecuadas para establecer un adecuado sistema de representación. Por tanto, habría que decir que el correcto manejo de la participación y la deliberación en el orden de la ética de máximos es también fundamental para la definición de 
los contenidos propios de la ética de mínimos. Aquí también la tarea de la bioética es sencillamente enorme.

De lo anterior se concluye que los contenidos de la ética de mínimos deben establecerse, en una sociedad democrática, mediante consensos logrados, bien directamente, bien mediante los representantes políticos. Dicho de otra manera: los contenidos de los principios de No-maleficencia y de Justicia que vayan a expresarse en forma de Derecho y a exigirse coactivamente a todos, deben establecerse mediante procedimientos que tengan en su base procesos de participación y de deliberación. En cualquier otro caso, los valores de una persona o un grupo estarán siendo impuestos, en última instancia por la fuerza, a todos los demás, lo que debe considerarse moralmente incorrecto. Esta es también una consecuencia del modelo democrático.

\section{Conclusión}

Personalmente opino que el éxito de la bioética se ha debido a la necesidad que la sociedad civil siente de reflexionar sobre las cuestiones de valor, participando activamente en los procesos de deliberación en torno a la gestión del cuerpo y de la vida de los seres humanos. Ya no pueden ser los médicos, ni los políticos, ni los economistas, ni tampoco los sacerdotes o los teólogos quienes detenten el monopolio de la deliberación y decisión en este tipo de cuestiones. Ha de ser la sociedad entera la que delibere y decida sobre ellas. La bioética debe verse, por ello, como un procedimiento para llevar la democracia participativa $\mathrm{y}$ deliberativa al espacio de la gestión de la vida y del cuerpo. Este tipo de decisiones ya no puede considerarse monopolio de nadie. Ha de ser la colectividad de los seres humanos la que intente definir sus deberes y obligaciones, mediante procedimientos participativos y deliberativos. Y la bioética debe verse como lo que es, un espacio intelectual y social para poder llevar esto a cabo. En este sentido, cabe decir que la bioética tiene vocación universalista, ya que considera que la toma de decisiones responsables en este área no puede lograrse más que por vía intersubjetiva, estimulando la participación de todos en el proceso de toma de decisiones. No es un azar que el padre de la bioética, Van Rensselaer Potter, haya sido el creador de otro término, que define perfectamente todo lo que estoy tratando de decir, el de Global Ethics, ética global. 
Democracia y bioética - D. Gracia G.

\section{Referencias}

1. Gracia D. Zubiri y la crisis de la razón. En: Álvarez A, Martínes R (eds). La filosofía de Zubiri en el contexto de la crisis europea. Santiago de Compostela: Universidad de Santiago de Compostela; 1996. pp. 39-51.

2. Weber M. El politico y el cientifico. Madrid: Alianza; 1969.

3. Artola M. Los derechos del hombre. Madrid: Alianza; 1986.

4. Habermas J. Facticidad y validez. Madrid: Trotta; 1998.

5. Habermas J. La inclusión del otro: estudios de teoría política. Barcelona: Paidos; 1999.

6. Kant I. Crítica de la razón práctica. Salamanca: Sígueme; 1994.

7. Kant I. Fundamentación de la metafísica de las costumbres. Barcelona: Ariel; 1996.

8. Jonas H. El principio de responsabilidad: ensayo de una ética para la civilización tecnológica. Barcelona: Círculo de Lectores; 1994.

9. Kant I. La paz perpetua. Apéndice I, Sobre el desacuerdo que hay entre la moral y la política con respecto a la paz perpetua. Madrid: Espasa-Calpe; 1964.

10. Gracia D. Bioética clínica. Ética y vida: estudios de bioética. vol. 2. Bogotá: El Búho; 1998.

11. Aristóteles. Política I,1: 1252 a 1.

12. Gutmann A. La educación democrática: una teoría política de la educación. Barcelona: Paidos; 2001.

13. Laporta F. Los problemas de la democracia deliberativa. Claves de la razón práctica 2001; 109:22-8.

14. Nino CS. La constitución de la democracia deliberativa. Barcelona: Gedisa; 1997. 